\title{
Clinical significance of gelsolin-like actin-capping protein expression in oral carcinogenesis: an immunohistochemical study of premalignant and malignant lesions of the oral cavity
}

\author{
Hitomi Nomura ${ }^{1}$, Katsuhiro Uzawa*1,2, Takashi Ishigami ${ }^{1}$, Yukinao Kouzu${ }^{1}$, \\ Hirofumi Koike1, Katsunori Ogawara'1, Masashi Siiba1, Hiroki Bukawa², \\ Hidetaka Yokoe ${ }^{2}$, Hitoshi Kubosawa ${ }^{3}$ and Hideki Tanzawa1,2,4
}

\author{
Address: ${ }^{1}$ Department of Clinical Molecular Biology, Graduate School of Medicine, Chiba University, 1-8-1 Inohana, Chuo-ku, Chiba, 260-8670, \\ Japan, ${ }^{2}$ Division of Dentistry and Oral-Maxillofacial Surgery, Chiba University Hospital, 1-8-1 Inohana, Chuo-ku, Chiba, 260-8670, Japan, \\ ${ }^{3}$ Department of Pathology, Chiba Municipal Aoba Hospital, 1273-2 Aoba-cho, Chuo-ku, Chiba 260-0852, Japan and ${ }^{4}$ Center of Excellence (COE) \\ Program in the 21st Century, Graduate School of Medicine, Chiba University, 1-8-1 Inohana, Chuo-ku, Chiba, 260-8670, Japan \\ Email: Hitomi Nomura - nomu@graduate.chiba-u.jp; Katsuhiro Uzawa* - uzawak@faculty.chiba-u.jp; \\ Takashi Ishigami - takashi.ishigami@graduate.chiba-u.jp; Yukinao Kouzu - y.kouzu@hotmail.co.jp; Hirofumi Koike - koisai-man@goo.jp; \\ Katsunori Ogawara - katsunori.ogawara@faculty.chiba-u.jp; Masashi Siiba - m.shiiba@faculty.chiba-u.jp; Hiroki Bukawa - bukawah- \\ cuh@umin.ac.jp; Hidetaka Yokoe - yokoe@faculty.chiba-u.jp; Hitoshi Kubosawa - hitoshi-kubosawa@city.chiba.jp; \\ Hideki Tanzawa - tanzawap@faculty.chiba-u.jp \\ * Corresponding author
}

Published: I February 2008

BMC Cancer 2008, 8:39 doi:10.1 |86/147|-2407-8-39
Received: 4 July 2007

Accepted: I February 2008

This article is available from: http://www.biomedcentral.com/I47I-2407/8/39

(C) 2008 Nomura et al; licensee BioMed Central Ltd.

This is an Open Access article distributed under the terms of the Creative Commons Attribution License (http://creativecommons.org/licenses/by/2.0), which permits unrestricted use, distribution, and reproduction in any medium, provided the original work is properly cited.

\begin{abstract}
Background: Gelsolin-like actin-capping protein (CapG) is a ubiquitous gelsolin-family actin-modulating protein involved in cell signalling, receptor-mediated membrane ruffling, phagocytosis, and motility. CapG has generated great interest due to its oncogenic function in the control of cell migration or invasion in a variety of cancer cells. We previously applied proteomic methods to characterize differentially expressed proteins in oral squamous-cell carcinoma (OSCC) cells and detected significantly high expression levels of CapG in OSCC-derived cell lines compared to human normal oral keratinocytes. In the current study, to further determine the potential involvement of CapG in OSCC, we evaluated the status of CapG protein and mRNA expression in human oral premalignant lesions (OPLs) and primary OSCCs and correlated the results with clinicopathologic variables.
\end{abstract}

Methods: Matched normal and tumour tissue sections of 79 human primary OSCCs and 28 OPLs were analyzed for CapG expression by immunohistochemistry (IHC). Correlations between CapG-immunohistochemical staining scores of OSCCs and clinicopathologic features were evaluated by Fisher's exact test. Real-time quantitative reverse transcriptase-polymerase chain reaction (qRT-PCR) was used to estimate CapG expression at the mRNA level.

Results: In IHC, substantial up-regulation of CapG protein was observed in primary OSCCs (52\%) and OPLs (64\%), whereas corresponding normal tissues showed consistently weak or absent immunoreactivity of CapG. qRT-PCR data were consistent with the protein expression status. Moreover, CapG expression was correlated with the TNM stage grading of OSCCs.

Conclusion: Our finding of frequent dysregulated expression of CapG in premalignant and malignant lesions together with an association with an advanced clinical disease stage suggests that CapG could contribute to cancer development and progression and that CapG may have potential as a biomarker and a therapeutic target for OSCC. 


\section{Background}

Oral squamous cell carcinoma (OSCC) is a major cause of morbidity and mortality globally, accounting for 275,000 new cases and more than 120,000 deaths annually [1-3]. Despite therapeutic and diagnostic advances, patients often are diagnosed at advanced stages and mortality rates are still increasing [4]. This highlights the need for continued efforts to discover suitable biomarkers for early disease diagnosis and to understand the disease pathogenesis as a first step toward improving treatment. Considering these problems, it is imperative to study oral carcinomas at the genetic level and to characterize the genetic changes responsible for carcinogenesis and tumour behaviour.

Because proteomics-based profiling uniquely allows delineation of global changes in expression patterns resulting from transcriptional and posttranscriptional control and posttranslational modifications, proteomic tolls are used increasingly in the post-genomic era to discover new cancer biomarkers $[5,6]$. We recently developed a strategy of using proteomics technologies to search for significant molecular biomarkers characteristic of oral carcinogenesis [7-10]. Among the proteins identified, CapG expression was found to be up-regulated in OSCC-derived cell lines compared to human normal oral keratinocytes using a fluorescent two-dimensional differential in-gel electrophoresis (2-D-DIGE) system and matrix-assisted laser desorption/ionization time-of-flight mass spectrometry (MALDI-TOF/MS).

CapG, also known as macrophage capping protein, is a 348-amino acid protein that is ubiquitously expressed in normal tissues and particularly abundant in macrophages [11-13]. CapG is a member of the actin-binding protein, which is crucial for the organization of the actin cytoskeleton. The actin cytoskeleton underlies many cellular functions including the maintenance and mutability of cell shape, motility, adherence, and growth regulation [1416]. Since these cellular functions have escaped normal control mechanisms during carcinogenesis, the behaviour of actin and actin-binding proteins has undergone intense scrutiny as a potential contributor to malignant transformation and a target for anticancer drug development [1719]. Evidence indicates that CapG also possesses an oncogenic function involved in the control of cell migration or invasion, and we hypothesized that the protein has potential as an emerging therapeutic target of interest for the treatment of oral cancer. However, it is unclear whether CapG is associated with oral carcinogenesis. The purpose of the current study was to determine CapG protein/ mRNA expression in a series of human primary OSCCs and human oral premalignant lesions(OPLs) and correlate the protein expression with the clinical relevance in patients with OSCC.

\section{Methods \\ Tissue specimens}

Seventy-nine pairs of primary OSCC samples and corresponding normal oral epithelium tissues or 28 OPLs (diagnosed as oral leukoplakias) were obtained at the time of surgery performed at Chiba University Hospital between 1998 and 2006. All patients provided informed consent according to the protocol that was reviewed and approved by the institutional review board of Chiba University before any procedures were performed. The resected tissues were divided into two parts: one was frozen immediately after removal of the surrounding normal tissue and stored at $-80^{\circ} \mathrm{C}$ until RNA extraction, and another was fixed in $10 \%$ buffered formaldehyde solution for pathologic diagnosis and immunohistochemical staining. Histopathologic diagnosis of each tumour specimen was carried out according to the International Histological Classification of Tumors by the Department of Pathology, Chiba University Hospital. Clinicopathologic staging was determined by the TNM classification of the International Union against Cancer. All OSCC samples were histologically confirmed and checked to ensure the presence of tumour in greater than $80 \%$ of specimens.

\section{Cell culture}

The OSCC-derived cell lines used in this study were HSC2, HSC-3, and Ca9-22 (Human Science Research Resources Bank, Osaka, Japan). All OSCC-derived cell lines were cultured in Dulbecco's modified Eagle medium F-12 HAM (Sigma-Aldrich Co.), supplied with 10\% heatinactivated fetal bovine serum (Sigma) and $50 \mathrm{U} / \mathrm{ml}^{-1}$ penicillin and streptomycin (Sigma), and incubated at $37^{\circ} \mathrm{C}$ in a humidified atmosphere with $5 \% \mathrm{CO}_{2}$.

\section{Protein and mRNA extraction}

Protein was extracted when the cells reached $80 \%$ to $90 \%$ confluence; they were washed twice with phosphate buffered saline (PBS), scraped into a tube, and centrifuged briefly. The cell pellets were incubated for $30 \mathrm{~min}$ in a lysis buffer containing $7 \mathrm{M}$ urea, $2 \mathrm{M}$ thiourea, 4\% w/v CHAPS, and $10 \mathrm{mM}$ Tris $\mathrm{pH} 8.0$, and lysed by sonication $(3 \times 10$ sec pulses on ice). The sample was centrifuged at 13,000 rpm for $20 \mathrm{~min}$. The supernatant containing the cell proteins then was recovered and the protein concentration was measured with a Protein Assay Kit (Bio-Rad Laboratories) and adjusted to $1 \mathrm{mg} / \mathrm{ml}$ with lysis buffer. The $\mathrm{pH}$ of the protein sample was adjusted to 8.5 with $30 \mathrm{mM}$ Tris$\mathrm{HCl}$. Total RNA was extracted using Trizol Reagent (Invitrogen Life Technologies) according to the manufacturer's instructions. Each extracted RNA or protein was stored separately at $-80^{\circ} \mathrm{C}$ until use.

\section{Immunohistochemistry}

To examine the cellular distribution of CapG protein in oral lesions, we carried out immunohistochemical stain- 
ing on $4-\mu \mathrm{m}$ sections of paraffin-embedded specimens. Briefly, after deparaffinization and hydration, the slides were pretreated in $10 \mathrm{mM}$ sodium citrate buffer ( $\mathrm{pH} 6.0$ ) in a microwave oven for $5 \mathrm{~min}$ at $95^{\circ} \mathrm{C}$. The endogenous peroxidase activity was quenched by $30-\mathrm{min}$ incubation in a mixture of $0.3 \%$ hydrogen peroxide solution in $100 \%$ methanol. After being washed with PBS buffer, the sections then were incubated with primary antibody affinitypurified goat antihuman CAPG polyclonal antibody (1:500 dilution; Santa Cruz Biotechnology, Santa Cruz, CA; catalogue number: sc-33084) at room temperature in a moist chamber overnight. After being washed with PBS buffer, the slides were treated with biotinylated secondary antibody for $1 \mathrm{hr}$ followed by colour development in 3, 3'diaminobenzidine tetrahydrochloride (DAKO JAPAN Inc., Kyoto, Japan). Finally, the slides were lightly counterstained with hematoxylin. A negative control was established by replacing the primary antibody with PBS. To quantitate the state of CapG protein expression, the mean percentage of positive tumour cells was determined in at least five random fields at $400 \times$ magnification in each section. The intensity of the CapG immunoreaction was scored as follows: 1+, weak; 2+, moderate; and 3+, intense. Three target cell types, i.e., normal, premalignant, and malignant epithelial cells, were identified for scoring. The percentage of CapG-positive cells and the staining intensity then were multiplied to establish a CapG-immunohistochemical (CapG-IHC) staining score. Cases with a CapG-IHC score exceeding 78.68 (maximum score of normal tissues) were considered positive. Two independent pathologists, neither of whom had knowledge of the patients' clinical status, made these judgments.

\section{Western blot analysis}

To confirm the specificity of the CapG antibody used, three Western blot examinations were carried out on three OSCC-derived cell lines (HSC-2, HSC-3, and Ca9-22). Protein extracts were electrophoresed on $11 \%$ sodium dodecyl sulfate-polyacrylamide gel electrophoresis gels, transferred to polyvinylidene difluoride (PVDF) membranes (Bio-Rad), and blocked for $1 \mathrm{hr}$ at room temperature in 5\% skim milk. Immunoblot PVDF membranes were washed five times with $0.1 \%$ Tween 20 in TBS (TBS$\mathrm{T})$, and $2 \mu \mathrm{g}$ ml- 1 affinity-purified goat antihuman CAPG polyclonal antibody (1:5000 dilution; Santa Cruz Biotechnology) was added directly to the TBS-T solution for $2 \mathrm{hr}$ at room temperature. The PVDF membranes were washed again and incubated with 1:10,000 ratio of antigoat IgG (Nichirei Biosciences Inc., Tokyo, Japan; catalogue number: 414161) as a secondary antibody for 20 min at room temperature. The membranes then were incubated with Enhanced ChemiLuminescence (ECL)+ HRP HORSERADISH PEROXIDASE? substrate solution included in the ECL+ kit (Amersham Biosciences), and immunoblotting was visualized by exposing the membrane to Hyperfilm (Amersham Biosciences).

\section{mRNA expression analysis}

The expression levels of CapG mRNA were examined in 50 OSCC specimens from patients with primary tumours among the OSCC cases studied by IHC staining. Control reactions were prepared in parallel without reverse transcriptase (RT). Before cDNA synthesis, residual genomic DNA was removed from the total RNA using DNase I treatment (DNA-free; Ambion, Austin, TX). The primer sequences used to analyze CapG mRNA expression were 5CTCACAGCTGACAAGGCAAA-3 (nucleotides 965-984) and 5-CCACCCTCATTTCCAGTCC-3 (nucleotides 1303-1321). The sequences of specific primers were checked before use to avoid amplification of genomic DNA or pseudogenes by the Primer3 program [20]. Amplified products were analyzed by 3\% agarose gel electrophoresis to ascertain size and purity. Real-time quantitative RT-polymerase chain reaction (qRT-PCR) was performed with a single method using the LightCycler FastStart DNA Master SYBR Green I kit (Roche, Mannheim, Germany). To prepare the standard curve, $3 \mu \mathrm{g}$ of total RNA from normal oral tissue was reverse-transcribed with Superscript RT (Life Technologies, Grand Island, NY) and oligo-d(T)12-18 primer, after which serial dilutions were made corresponding to cDNA transcribed from 300, 30, 3.0, and 0.3 ng of total RNA. PCRs using LightCycler apparatus were carried out in a final volume of $20 \mu \mathrm{l}$ of reaction mixture consisting of $2 \mu \mathrm{l}$ of FirstStart DNA Master SYBR Green I mix, $3 \mathrm{mM} \mathrm{MgCl}_{2}$, and $0.2 \mu$ l of primers, according to the manufacturer's instructions. The reaction mixture then was loaded into glass capillary tubes and submitted to an initial denaturation at $95^{\circ} \mathrm{C}$ for $10 \mathrm{~min}$, followed by 45 rounds of amplification at $95^{\circ} \mathrm{C}(10 \mathrm{sec})$ for denaturation, $58^{\circ} \mathrm{C}(10 \mathrm{sec})$ for annealing, and $72{ }^{\circ} \mathrm{C}$ for extension, with a temperature slope of $20^{\circ} \mathrm{C} / \mathrm{sec}$, performed in the LightCycler. The transcript amount for $C a p G$ was estimated from the respective standard curves and normalized to the GAPDH transcript amount determined in corresponding samples.

\section{Statistical analysis}

Differences in gene expression levels between CapG-positive and CapG-negative cases were calculated with the Mann-Whitney's U-test. Correlations between CapG-IHC scores and clinicopathologic features were evaluated by Fisher's exact test. The criterion for statistical significance was $P<0.05$. Mean values are shown with the standard error.

\section{Results \\ Immunohistochemical analysis}

IHC staining was performed using a series of surgical specimens, including 79 OSCCs with corresponding normal 
tissues and 28 OPLs. Representative results for CapG protein expression in normal oral tissues, OPLs, and primary OSCCs are shown in Figure 1. Normal oral mucosal specimens had no or faint CapG immunoreactivity in almost all epithelium cells and were considered CapG-negative. In contrast, 41 of 79 (52\%) cases of OSCCs examined had significantly increased expression of CapG immunoreactivity in the nucleus and cytoplasm of the tumour cells (IHC score > 78.68; maximum score of normal tissues). In OPL specimens, positive CapG immunoreactivity was detected distinctly on spinous cells in 18 of 28 cases $(64 \%)$. Stromal components such as fibroblasts, lymphocytes, endothelial cells, and macrophages also exhibited positive CapG immunoreactivity, the last of which CapG is known to be homogeneously expressed in both normal and tumour specimens. In the current study, we focused on CapG expression in epithelium cells. The specificity of the primary antibody also was evaluated. A single band was recognized at the appropriate molecular weight of CapG protein on Western blot analysis as reported by Johnston et al [21] (see additional file 1). Furthermore, no IHC staining was observed when OSCC tissue was analyzed without the primary antibody (Figure 1D).

The CapG-IHC scores for normal tissues, OPLs, and OSCCs ranged from 0 to 79 (mean, 17.14), 6 to 204

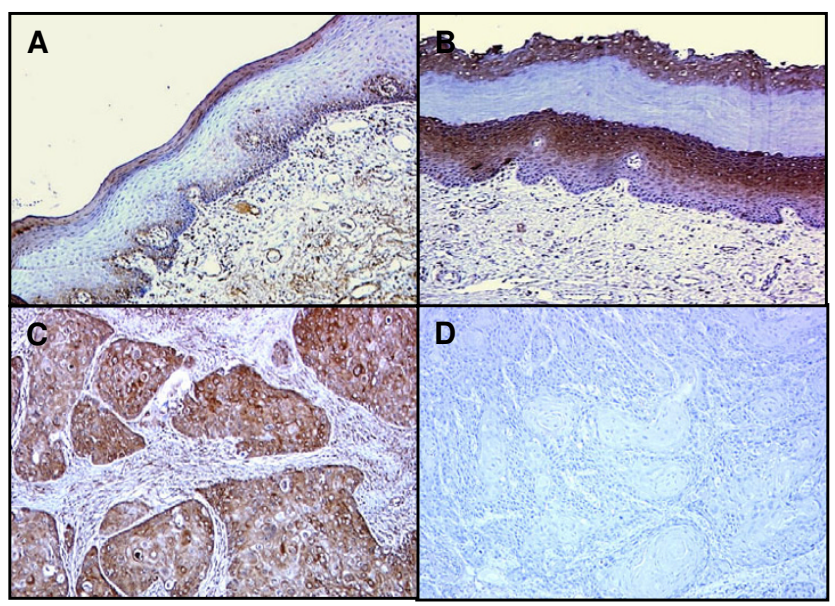

\section{Figure I}

Representative results of immunohistochemical staining of CapG in normal tissues, OPLs, and primary OSCCs. A: Normal oral tissue exhibits negative CapG protein expression (original magnification $\times 100$ ); $\mathrm{B}$ : CapG-positive case of OPL. The immunoreaction is enhanced in the spinous layer (original magnification $\times 100$ ); C: CapG-positive case of OSCC (stage IV). Strong positive immunoreactivity for CapG is detected in the nuclear and cytoplasm (original magnification $\times 200$ ); D: The same OSCC sample is immunostained in the absence of the primary antibody (original magnification $\times 200$ ). (mean, 65.36), and 3 to 287 (mean, 96.19), respectively. CapG expression levels in primary OSCCs and OPLs were significantly $(P<0.01)$ higher than those in normal oral tissues (Figure 2A). In contrast, there was no significant ( $P$ $=0.80$ ) difference in CapG-IHC scores between OSCCs and OPLs. The correlation between the clinicopathologic characteristics of the patients with OSCC and the status of CapG expression is summarized in Table 1. CapG protein expression was correlated with OSCC tumor size $(\mathrm{P}=$ 0.014). Moreover, the CapG-IHC scores for early stages (I and II) and advanc ed stages (III and IV) ranged from 3.62 to 160.3 (mean, 60.54) and 4.95 to 287.4 (mean, 107.4), respectively. The CapG expression levels were significantly higher in the OSCC group with advanced-stage disease compared with the group with early-stage disease (MannWhitney U-test, $\mathrm{P}<0.001$ ) (Figure 2B).

\section{mRNA expression analysis}

qRT-PCR analysis data were matched to protein expression levels studied by IHC scores. The CapG mRNA expression levels significantly increased in primary tumours of randomly selected CapG-positive cases ( $\mathrm{n}=$ 10) compared with randomly selected CapG-negative cases ( $\mathrm{n}=10$, Mann-Whitney U-test, $\mathrm{P}<0.001$ ) (Figure $2 \mathrm{C})$. The relative mRNA expression levels in negative and positive cases ranged from 0.16 to 1.15 (mean, 0.75 ) and 2.72 to 9.22 (mean, 5.67), respectively. Therefore, CapG mRNA expression levels were consistent with the protein expression.

\section{Discussion}

Tumour-associated processes such as invasion and metastasis are critically dependent on dynamic alterations in the organization of the actin cytoskeleton. Dysregulation of actin-based motility is a prominent factor in cell transformation and probably is associated with carcinogenesis $[22,23]$. To date, a large number of actin-binding proteins have been cloned, many of which are involved in the malignant transformation process; and distinctive protein expression patterns of some of these genes in cancer and progressive carcinogenesis processes have been observed [24-28]. Previously, we reported significant overexpression of the actin-binding protein CapG expression at the protein level in OSCC-derived cell lines using a 2-D-DIGE system and MALDI-TOF/MS [7].

CapG is a member of the gelsolin superfamily of the actinbinding proteins [29]. In addition to respective roles in actin filament remodelling, the proteins of the gelsolin superfamily have specific roles in several cellular processes, including cell motility, signal control, and apoptosis and regulation of phagocytosis [30,31]. Variations in expression of the gelsolin superfamily proteins are thought to affect major cytoskeletal changes during differentiation and carcinogenesis, and considerable evidence 
A

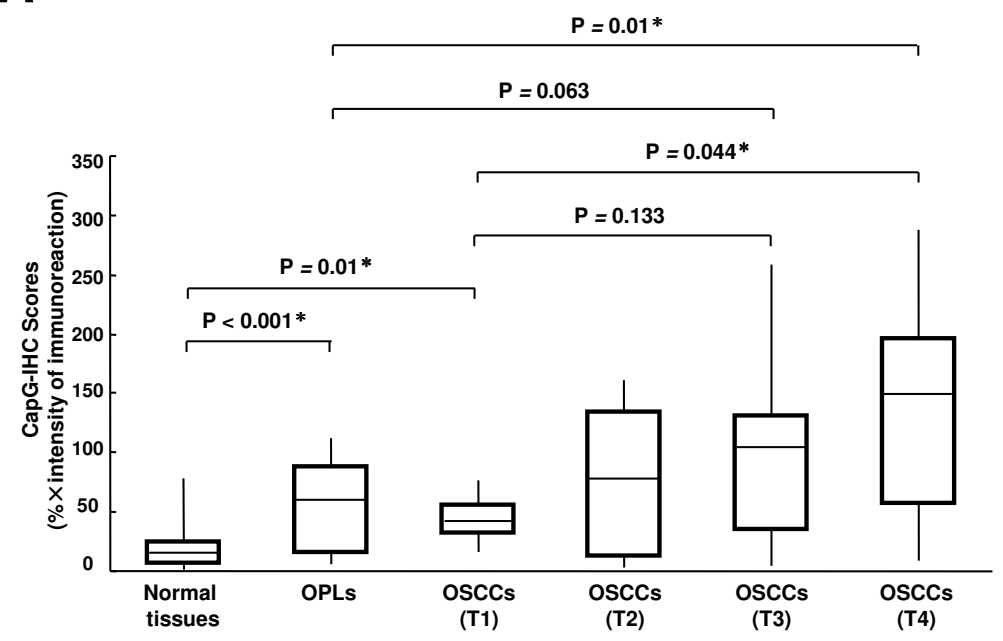

B
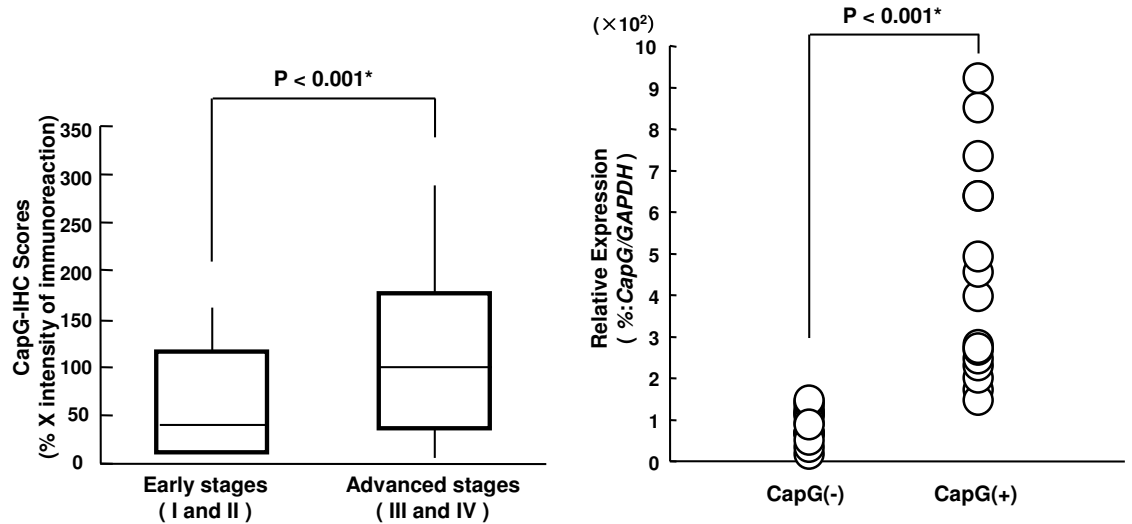

Figure 2

CapG protein and mRNA expression in normal tissues, OPLs, and primary OSCCs. A: CapG protein expression in OPLs $(n=28)$ and OSCCs $(n=79)$ is significantly higher than in normal oral tissues $(n=79 ; P<0.01$, Mann-Whitney's $U$-test). The results are expressed as the mean \pm SD; B: States of CapG protein expression in early-stage (I and II) OSCC $(n=27)$ and advanced stages (III and IV) OSCC $(n=52)$ are compared. CapG protein expression in advanced stages is significantly higher than in the early stages $(P<0.001$, Mann-Whitney U-test); $C$ : Comparison of CapG mRNA expression levels between CapGpositive and CapG-negative cases in primary OSCCs classified by IHC analysis. There is a significant difference in the CapG mRNA expression levels between the negative and positive cases $(P<0.00 I$, Mann-Whitney's $U$-test $)$.

has shown a significant association between the proteins and a wide range of human malignancies including OSCCs [32-35]. Experimental evidence has shown that CapG also is crucial for regulating cell motility [36,37]; however, its exact function in the development and progression of malignant tumours remains controversial. Watari et al. reported an apparent decrease in CapG protein levels in some human tumor cell lines compared with their corresponding benign counterparts. In addition, those investigators showed that CapG protein expression reduces the ability of a transformed cell to induce tumour formation, suggesting that CapG is a tumour suppressor gene [38]. However, accumulating evidence has indicated a number of theories on the possible function of CapG as a tumor activator. A recent study identified CapG as a target of the AP-1 transcription factor complex, which has emerged as a critical regulator of gene expression in response to the activation of a variety of oncogenic signal transduction cascades, including c-Fos and c-Jun [39]. De Corte et al. reported that overexpression of CapG pro- 
Table I: Correlation between the Expression of CapG and Clinical Classification in OSCCs.

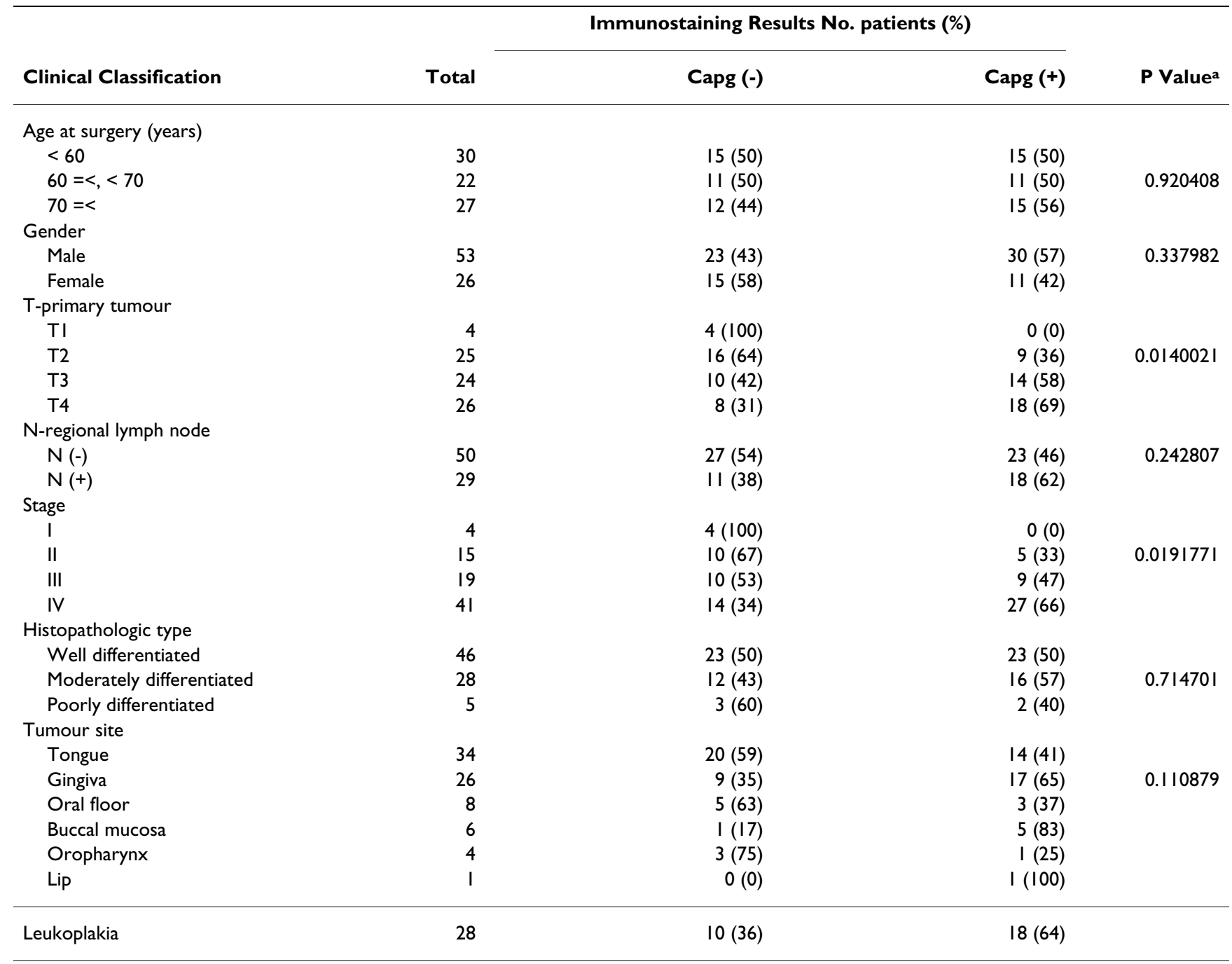

aP $<0.05$ was considered significant.

motes cancer cells to invade collagen through the Rasphosphoinositide 3-kinase signaling pathway [40]. More recently, they reported that targeting human cancer cells, including breast and prostate cancer cells with an RNAi procedure against CapG, significantly reduced the invasive and motile properties of both cells examined as well as cell aggregation [41]. Similar results were obtained by others in pancreatic cancer cells [42]. These findings support the hypothesis that CapG also is a tumour activator. Furthermore, significant overexpression of CapG was reported at both the mRNA and protein levels in several types of human primary tumours, i.e., ocular melanomas [43], glioblastomas [44], and pancreatic ductal adenocarcinomas [42], all of which are aggressive cancers that kill patients by metastasis and local invasion. Because OSCC is also a solid neoplasm exhibiting aggressive tumour phenotypes, we hypothesized that CapG is a potential emerging therapeutic target of interest for the treatment of oral cancer. However, the status of CapG in OSCC remains unclear and therefore we selected it for further investigation.

To confirm our hypothesis, we determined the protein/ mRNA expression in a series of human primary OSCCs using IHC. By evaluating the CapG-IHC scores, significant up-regulation was evident in the primary OSCCs compared with normal tissues $(\mathrm{P}<0.01)$. The CapG protein expression levels in primary OSCCs were significantly associated with tumor size $(\mathrm{P}=0.014)$. In pancreatic ductal adenocarcinomas, a clinical study also showed that high CapG expression was correlated with increased tumour size [42], which was consistent with results obtained in the current study. Moreover, the state of CapG protein expression differed significantly between the early stages (I and II) and the advanced stages (III and IV) (Mann-Whitney U-test, $\mathrm{P}<0.001$ ). Given the known roles 
of CapG in cytoskeletal organization and cell migration, these findings indicated the potential clinical significance of CapG as a marker or prospective therapeutic target for the most aggressive forms of OSCCs. Furthermore, high levels of CapG protein expression were detected even in the OPLs examined, suggesting that CapG may play an important role in early-stage OSCC development. However, the development of OSCC is generally predicated on the development of multiple clonal genetic alterations $[45,46]$, and additional research is needed to establish whether and how CapG-stained OPLs give rise to strongly CapG-stained OSCCs.

\section{Conclusion}

Significant overexpression of the actin-binding protein CapG was detected not only in $52 \%$ of OSCCs but also in $64 \%$ of OPLs. Enhanced expression of CapG was associated with large tumour size and advanced staging of OSCCs. Based on our data, we concluded that CapG may initiate or activate the neoplastic process of OSCC cells including the regulation of biologic behaviour of aggressive forms of cells rather than as a suppressor. In addition, CapG may serve as a useful diagnostic biomarker or a therapeutic target to identify and treat patients with advanced OSCCs. The current results together with previously reported evidence suggest that CapG provides an attractive molecular target for decreasing invasiveness and the metastatic properties of tumors. Further studies may provide insights into the process of tumorigenicity and for planning new treatment strategies.

\section{Abbreviations}

CapG, gelsolin-like actin capping protein; OSCC, oral squamous-cell carcinoma; OPL, human oral premalignant lesion;IHC, immunohistochemistry; qRT-PCR, realtime quantitative reverse transcriptase-polymerase chain reaction; 2-D-DIGE, two-dimensional differential in-gel electrophoresis; MALDI-TOF/MS, matrix-assisted laser desorption/ionization time-of-flight mass spectrometry

\section{Competing interests}

The author(s) declare that they have no competing interests.

\section{Authors' contributions}

HN carried out and coordinated the study, conducted IHC and data analysis, and drafted the manuscript. KU participated in the study design, interpretation of data, and revision of the manuscript. TI, HK, and YK performed and evaluated the immunohistochemical analysis. KO isolated RNAs and performed qRT-PCR analysis. MS contributed to and supervised the statistical analysis. HB and HY were involved in the sample acquisition, sample selection, clinical data acquisition, and preparing the manuscript. HK did the pathology review. HT supervised and control- led the entire study. All authors reviewed and commented on successive drafts of the manuscript and approved the final manuscript.

\section{Additional material}

\section{Additional file 1}

Control experiments for CapG primary antibody used in IHC. Western blot examination of CapG protein in three OSCC-derived cell lines (HSC2, HSC-3, and Ca9-22) using the primary antibody used in IHC. All OSCC-derived cell line extracts exhibit a single band for CapG protein expression.

Click here for file

[http://www.biomedcentral.com/content/supplementary/14712407-8-39-S1.ppt]

\section{Acknowledgements}

We thank Lynda C. Charters for editing this manuscript. This study was supported partly by a Grant-in-Aid Scientific Research (No. 16209059) from the Ministry of Education, Culture, Sports, Science and Technology of Japan.

\section{References}

I. Sudbo J, Reith A: The evolution of predictive oncology and molecular-based therapy for oral cancer prevention. Int J Cancer 2005, I I 5:339-345.

2. Lippman SM, Sudbo J, Hong WK: Oral cancer prevention and the evolution of molecular-targeted drug development. J Clin Oncol 2005, 23:346-356.

3. Parkin DM, Bray F, Ferlay J, Pisani P: Global cancer statistics, 2002. CA Cancer J Clin 2005, 55:74-108.

4. La Vecchia C, Lucchini F, Negri E, Levi F: Trends in oral cancer mortality in Europe. Oral Oncol 2004, 40:433-439.

5. Chuthapisith S, Layfield R, Kerr ID, Eremin O: Principles of proteomics and its applications in cancer. Surgeon 2007, 5:14-22.

6. Cho WC: Contribution of oncoproteomics to cancer biomarker discovery. Mol Cancer 2007, 6:25.

7. Koike H, Uzawa K, Nakashima D, Shimada K, Kato Y, Higo M, Kouzu $Y$, Endo $Y$, Kasamatsu A, Tanzawa H: Identification of differentially expressed proteins in oral squamous cell carcinoma using a global proteomic approach. Int J Oncol 2005, 27:59-67.

8. Nakashima D, Uzawa K, Kasamatsu A, Koike H, Endo Y, Saito K, Hashitani S, Numata T, Urade M, Tanzawa H: Protein expression profiling identifies maspin and stathmin as potential biomarkers of adenoid cystic carcinoma of the salivary glands. Int J Cancer 2006, I I 8:704-7| 3 .

9. Kasamatsu A, Uzawa K, Nakashima D, Kouzu Y, Endo $Y$, Koike H, Yokoe $H$, Harada K, Sato M, Tanzawa $H$ : A proteomics approach to characterizing human submandibular gland cell lines by fluorescent two-dimensional differential in-gel electrophoresis. Int J Mol Med 2006, 17:253-260.

10. Kato H, Uzawa K, Onda T, Kato Y, Saito K, Nakashima D, Ogawara K, Bukawa $H$, Yokoe $H$, Tanzawa H: Down-regulation of ID-myoinositol 1,4,5-trisphosphate 3-kinase $A$ protein expression in oral squamous cell carcinoma. Int J Oncol 2006, 28:873-88I.

11. Yu FX, Johnston PA, Sudhof TC, Yin HL: gCap39, a calcium ionand polyphosphoinositide-regulated actin capping protein. Science 1990, 250:|413-1415.

12. Prendergast GC, Ziff EB: Mbh I: a novel gelsolin/severin-related protein which binds actin in vitro and exhibits nuclear localization in vivo. EMBO J 1991, 10:757-766.

13. Dabiri GA, Young CL, Rosenbloom J, Southwick FS: Molecular cloning of human macrophage capping protein cDNA. A unique member of the gelsolin/villin family expressed primarily in macrophages. J Biol Chem 1992, 267:16545-16552. 
14. Pollard TD, Borisy GG: Cellular motility driven by assembly and disassembly of actin filaments. Cell 2003, I | 2:453-465.

15. Welch MD, Mullins RD: Cellular control of actin nucleation. Annu Rev Cell Dev Biol 2002, 18:247-288.

16. Janmey PA: The cytoskeleton and cell signaling: component localization and mechanical coupling. Physiol Rev 1998, 73(3):763-78I.

17. Maruta $\mathrm{H}, \mathrm{He} \mathrm{H}$, Tikoo A, Vuong $\mathrm{T}$, Nur-E-Kamal M: G proteins, phosphoinositides, and actin-cytoskeleton in the control of cancer growth. Microsc Res Tech 1999, 47:61-66.

18. Janmey Paul A: Medical aspects of the actin cytoskeleton. Curr Opin Cell Biol 1995, 7: I II-I I7.

19. Rao J, Li N: Microfilament actin remodeling as a potential target for cancer drug development. Curr Cancer Drug Targets 2004, 4:345-354.

20. Primer3 [http://www-genome.wi.mit.edu/cgi-bin/primer/ primer3 www.cgi]

21. Johnston PA, Yu FX, Reynolds GA, Yin HL, Moomaw CR, Slaughter CA, Südhof TC: Purification and expression of gCap39. An intracellular and secreted $\mathrm{Ca2(+)}$-dependent actin-binding protein enriched in mononuclear phagocytes. I Biol Chem 1990, 265: I7946-17952.

22. Kassis J, Lauffenburger DA, Turner T, Wells A: Tumor invasion as dysregulated cell motility. Semin Cancer Biol 200 I, I I: I05-I I7.

23. Yamazaki D, Kurisu S, Takenawa T: Regulation of cancer cell motility through actin reorganization. Cancer Sci 2005, 96:379-386.

24. Kikuchi S, Yamada D, Fukami T, Masuda M, Sakurai-Yageta M, Williams $Y N$, Maruyama $T$, Asamura $H$, Matsuno $Y$, Onizuka $M$, Murakami Y: Promoter methylation of DAL-I/4.IB predicts poor prognosis in non-small cell lung cancer. Clin Cancer Res 2005, II:2954-296 I.

25. Yoder BJ, Tso E, Skacel M, Pettay J, Tarr S, Budd T, Tubbs RR, Adams JC. Hicks DG: The expression of fascin, an actin-bundling motility protein, correlates with hormone receptor-negative breast cancer and a more aggressive clinical course. Clin Cancer Res 2005, I I: | 86- 192.

26. Honda K, Yamada T, Hayashida Y, Idogawa M, Sato S, Hasegawa F, Ino $Y$, Ono M, Hirohashi S: Actinin-4 increases cell motility and promotes lymph node metastasis of colorectal cancer. Gastroenterology 2005, 1 28:51-62.

27. Dunn TA, Chen S, Faith DA, Hicks JL, Platz EA, Chen Y, Ewing CM, Sauvageot J, Isaacs WB, De Marzo AM, Luo J: A novel role of myosin VI in human prostate cancer. Am J Pathol 2006, 169:1843-1854.

28. Kobayashi H, Sagara J, Kurita H, Morifuji M, Ohishi M, Kurashina K, Taniguchi S: Clinical significance of cellular distribution of moesin in patients with oral squamous cell carcinoma. Clin Cancer Res 2004, 10:572-580.

29. Sun HQ, Yamamoto M, Mejillano M, Yin HL: Gelsolin, a multifunctional actin regulatory protein. I Biol Chem 1999 274:33179-33182

30. Silacci P, Mazzolai L, Gauci C, Stergiopulos N, Yin HL, Hayoz D: Gelsolin superfamily proteins: key regulators of cellular functions. Cell Mol Life Sci 2004, 6 I:26 I 4-2623.

31. McGough AM, Staiger CJ, Min JK, Simonetti KD: The gelsolin family of actin regulatory proteins: modular structures, versatile functions. FEBS Lett 2003, 552:75-8I.

32. Yang J, Ramnath N, Moysich KB, Asch HL, Swede H, Alrawi SJ, Huberman J, Geradts J, Brooks JS, Tan D: Prognostic significance of MCM2, Ki-67 and gelsolin in non-small cell lung cancer. $B M C$ Cancer 2006, 6:203.

33. Winston JS, Asch HL, Zhang PJ, Edge SB, Hyland A, Asch BB: Downregulation of gelsolin correlates with the progression to breast carcinoma. Breast Cancer Res Treat 200I, 65:II-2I.

34. Noske A, Denkert C, Schober H, Sers C, Zhumabayeva B, Weichert W, Dietel M, Wiechen K: Loss of gelsolin expression in human ovarian carcinomas. Eur J Cancer 2005, 41:46I-469.

35. Shieh DB, Chen IW, Wei TY, Shao CY, Chang HJ, Chung CH, Wong TY, Jin YT: Tissue expression of gelsolin in oral carcinogenesis progression and its clinicopathological implications. Oral Oncol 2006, 42:599-606.

36. Pellieux C, Desgeorges A, Pigeon CH, Chambaz C, Yin H, Hayoz D, Silacci P: CapG, a gelsolin family protein modulating protective effects of unidirectional shear stress. J Biol Chem 2003, 278(3 I):29|36-29|44. Epub 2003 May 17.
37. Sun HQ, Kwiatkowska K, Wooten DC, Yin HL: Effects of CapG overexpression on agonist-induced motility and second messenger generation. J Cell Biol I995, I 29(I): I47-I56.

38. Watari A, Takaki K, Higashiyama S, Li Y, Satomi Y, Takao T, Tanemura A, Yamaguchi Y, Katayama I, Shimakage M, Miyashiro I, Takami K, Kodama K, Yutsudo M: Suppression of tumorigenicity, but not anchorage independence, of human cancer cells by new candidate tumor suppressor gene CapG. Oncogene 2006, 25:7373-7380.

39. Bahassi el M, Karyala S, Tomlinson CR, Sartor MA, Medvedovic M, Hennigan RF: Critical regulation of genes for tumor cell migration by AP-I. Clin Exp Metastasis 2004, 21:293-304.

40. De Corte V, Van Impe K, Bruyneel E, Boucherie C, Mareel M, Vandekerckhove J, Gettemans J: Increased importin-betadependent nuclear import of the actin modulating protein CapG promotes cell invasion. J Cell Sci 2004, I I 7:5283-5292.

4I. Van den Abbeele A, De Corte V, Van Impe K, Bruyneel E, Boucherie C, Bracke M, Vandekerckhove J, Gettemans J: Downregulation of gelsolin family proteins counteracts cancer cell invasion in vitro. Cancer Lett 2007, 255:57-70.

42. Thompson CC, Ashcroft FJ, Patel S, Saraga G, Vimalachandran D, Prime W, Campbell F, Dodson A, Jenkins RE, Lemoine NR, Crnogorac-Jurcevic T, Yin HL, Costello E: Pancreatic cancer cells overexpress gelsolin family-capping proteins, which contribute to their cell motility. Gut 2007, 56:95-106.

43. Van Ginkel PR, Gee RL, Walker TM, Hu DN, Heizmann CW, Polans AS: The identification and differential expression of calciumbinding proteins associated with ocular melanoma. Biochim Biophys Acta 1998, 1448:290-297.

44. Lal A, Lash AE, Altschul SF, Velculescu V, Zhang L, McLendon RE, Marra MA, Prange C, Morin PJ, Polyak K, Papadopoulos N, Vogelstein B, Kinzler KW, Strausberg RL, Riggins GJ: A public database for gene expression in human cancers. Cancer Res 1999 , 59:5403-5407.

45. Mithani SK, Mydlarz WK, Grumbine FL, Smith IM, Califano JA: Molecular genetics of premalignant oral lesions. Oral Dis 2007. 13:126-133.

46. Califano J, Westra WH, Meininger G, Corio R, Koch WM, Sidransky $D:$ Genetic progression and clonal relationship of recurrent premalignant head and neck lesions. Clin Cancer Res 2000, 6:347-352.

\section{Pre-publication history}

The pre-publication history for this paper can be accessed here:

\section{http://www.biomedcentral.com/1471-2407/8/39/prepub}

Publish with BioMed Central and every scientist can read your work free of charge

"BioMed Central will be the most significant development for disseminating the results of biomedical research in our lifetime. "

Sir Paul Nurse, Cancer Research UK

Your research papers will be:

- available free of charge to the entire biomedical community

- peer reviewed and published immediately upon acceptance

- cited in PubMed and archived on PubMed Central

- yours - you keep the copyright

Submit your manuscript here:

http://www.biomedcentral.com/info/publishing_adv.asp
BioMedcentral 